Pacific Journal of Mathematics

ON UNIFORM CONVERGENCE FOR WALSH-FOURIER
SERIES 


\section{ON UNIFORM CONVERGENCE FOR WALSH-FOURIER SERIES}

\section{W. ONNEWEER}

In $1940 \mathrm{R}$. Salem formulated a sufficient condition for a continuous and periodic function to have a trigonometric Fourier series which converges uniformly to the function. In this paper we will formulate a similar condition, which implies that the Walsh-Fourier series of such a function has this property. Furthermore we show that our result is stronger than certain classical results, and that it also implies the uniform convergence of the Walsh-Fourier series of certain classes of continuous functions of generalized bounded variation. The latter is analogous to results obtained by $L$. C. Young and R. Salem for trigonometric Fourier series.

Let $\left\{\varphi_{n}(x)\right\}$ be the sequence of Rademacher functions, i.e.,

$$
\begin{aligned}
& \varphi_{0}(x)=+1\left(0 \leqq x<\frac{1}{2}\right), \quad \varphi_{0}(x)=-1\left(\frac{1}{2} \leqq x<1\right), \\
& \varphi_{0}(x+1)=\varphi_{0}(x) .
\end{aligned}
$$

$\varphi_{n}(x)=\varphi_{0}\left(2^{n} x\right),(n=1,2,3, \cdots)$. In [3] R. E. A. C. Paley gave the following definition for the Walsh functions $\left\{\psi_{n}(x)\right\}: \psi_{0}(x) \equiv 1$, and, if $n=2^{n_{1}}+2^{n_{2}}+\cdots+2^{n_{r}}$, with $n_{1}>n_{2}>\cdots>n_{r}$, then $\psi_{n}(x)=$ $\varphi_{n_{1}}(x) \varphi_{n_{2}}(x) \cdots \varphi_{n_{r}}(x)$. J. L. Walsh [6] proved that the system $\left\{\psi_{n}(x)\right\}$ is a complete orthonormal system. For every Lebesgue-integrable function $f(x)$ of period 1 there is a corresponding Walsh-Fourier series (WFS):

$$
f(x) \sim \sum_{k=0}^{\infty} c_{k} \psi_{k}(x), \quad \text { with } \quad c_{k}=\int_{0}^{1} f(t) \psi_{k}(t) d t .
$$

As in the case of trigonometric Fourier series (TFS), we can find a simple expression for the partial sums of a WFS,

$$
S_{n}(f, x)=\sum_{k=0}^{n-1} c_{k} \psi_{k}(x)=\int_{0}^{1} f(x+t) D_{n}(t) d t,
$$

where $D_{n}(t)=\sum_{k=0}^{n=1} \psi_{k}(t)$. For the meaning of + and for further notations, definitions and properties of the WFS we refer to [2].

2. In [4], Chapter VI, R. Salem proved the following theorem: Let $f(x)$ be a continuous function of period $2 \pi$. For odd $n$, let

$$
T_{n}(x)=\sum_{p=0}^{(n-1) / 2}(p+1)^{-1}[f(x+2 p \pi / n)-f(x+(2 p+1) \pi / n)]
$$


and let $Q_{n}(x)$ be obtained from $T_{n}(x)$ by changing $\pi$ into $-\pi$. Then, if $\lim _{n \rightarrow \infty} T_{n}(x)=\lim _{n \rightarrow \infty} Q_{n}(x)=0$ uniformly in $x$, the TFS of $f(x)$ converges uniformly to $f(x)$. R. Salem also showed that this theorem implies both the Dini-Lipschitz test for continuous functions with modulus of continuity $\omega(f, \delta)=o\left(\log \delta^{-1}\right)^{-1}$ as $\delta \rightarrow 0$, and Jordan's theorem on continuous functions of bounded variation. Finally, he extended this last theorem to certain classes of continuous functions of generalized bounded variation. For a proof of Salem's results, see also [1], Chapter IV, $\S 5$.

3. Our main result about WFS can be stated as follows:

THEOREM. Let $f(x)$ be a continuous function of period 1 . Let

$$
U_{n}(x)=\sum_{p=1}^{2^{n}-1} p^{-1}\left|f\left(x+2 p / 2^{n+1}\right)-f\left(x+(2 p+1) / 2^{n+1}\right)\right| .
$$

Then, $\lim _{n \rightarrow \infty} U_{n}(x)=0$ uniformly in $x$ implies that $\lim _{k \rightarrow \infty} S_{k}(f, x)=$ $f(x)$ uniformly in $x$.

Proof. For each natural number $k$ we have

$$
S_{k}(f, x)-f(x)=\int_{0}^{1} D_{k}(t)[f(x+t)-f(x)] d t .
$$

Let $k=2^{n}+k^{\prime}$, with $0 \leqq k^{\prime}<2^{n}$, then, according to [2], p. 386, we have $D_{k}(t)=D_{2^{n}}(t)+\psi_{2^{n}}(t) \cdot D_{k^{\prime}}(t)$, where

$$
D_{2^{n}}(t)=\left\{\begin{array}{l}
2^{n} \text { on }\left[0,2^{-n}\right) \\
0 \text { on }\left[2^{-n}, 1\right)
\end{array}, D_{k^{\prime}}(t)=k^{\prime} \text { on }\left[0,2^{-n}\right),\right.
$$

and

$$
\psi_{2^{n}}(t)=\left\{\begin{array}{l}
+1 \text { on }\left[2 p / 2^{n+1},(2 p+1) / 2^{n+1}\right) \\
-1 \text { on }\left[(2 p+1) / 2^{n+1},(2 p+2) / 2^{n+1}\right)
\end{array} \text { for } p=0,1, \cdots, 2^{n}-1\right.
$$

Therefore,

$$
\begin{aligned}
\left|S_{k}(f, x)-f(x)\right| \leqq & \left|\int_{0}^{1} D_{2^{n}}(t)[f(x+t)-f(x)] d t\right| \\
& +\left|\int_{0}^{1} \psi_{2^{n}}(t) D_{k^{\prime}}(t)[f(x+t)-f(x)] d t\right|=A+B .
\end{aligned}
$$

For the first term of this sum we have 


$$
A \leqq 2^{n} \int_{0}^{2^{-n}}|f(x+t)-f(x)| d t \leqq \omega\left(f, 2^{-n}\right) .
$$

For the second term we have

$$
\begin{aligned}
B= & \mid \sum_{p=0}^{2^{n}-1}\left(\int_{2 p / 2^{n+1}}^{(2 p+1) / 2^{n+1}} D_{k^{\prime}}(t)[f(x+t)-f(x)] d t\right. \\
& \left.-\int_{(2 p+1) / 2^{n+1}}^{(2 p+2) / 2^{n+1}} D_{k^{\prime}}(t)[f(x+t)-f(x)] d t\right) \mid \\
= & \mid \sum_{p=0}^{2^{n}-1} \int_{2 p / 2^{n+1}}^{(2 p+1) / 2^{n+1}}\left(D_{k^{\prime}}(t)[f(x+t)-f(x)]\right. \\
& \left.-D_{k^{\prime}}\left(t+2^{-n-1}\right)\left[f\left(x+\left(t+2^{-n-1}\right)\right)-f(x)\right]\right) d t \mid .
\end{aligned}
$$

Now we observe that, since $k^{\prime}<2^{n}, D_{k^{\prime}}(t)$ is a sum of functions $\psi_{i}(t)$ with $i<2^{n}$. Each of these functions is constant on the intervals $\left[k / 2^{n},(k+1) / 2^{n}\right), \quad\left(k=0,1, \cdots, 2^{n}-1\right)$. Therefore, if $t \in\left[2 p / 2^{n+1},(2 p+1) / 2^{n+1}\right)$, then $D_{k^{\prime}}(t)=D_{k^{\prime}}\left(t+2^{-n-1}\right)=D_{k^{\prime}}\left(2 p / 2^{n+1}\right)$. Thus we have

$$
\begin{aligned}
B= & \left|\sum_{p=0}^{2^{n}-1} \int_{2 p / 2^{n+1}}^{(2 p+1) / 2^{n+1}} D_{k^{\prime}}\left(p / 2^{n}\right)\left[f(x+t)-f\left(x+\left(t+2^{-n-1}\right)\right)\right] d t\right| \\
= & \mid \sum_{p=0}^{2^{n}-1} \int_{0}^{2^{-n-1}} D_{k^{\prime}}\left(p / 2^{n}\right)\left[f\left(x+\left(t+2 p / 2^{n+1}\right)\right)\right. \\
& \left.-f\left(x+\left(t+(2 p+1) / 2^{n+1}\right)\right)\right] d t \mid \\
= & \mid \sum_{p=0}^{2^{n}-1} 2^{-n-1} \int_{0}^{1} D_{k^{\prime}}\left(p / 2^{n}\right)\left[f\left(x+(t+2 p) / 2^{n+1}\right)\right. \\
& \left.-f\left(x+(t+2 p+1) / 2^{n+1}\right)\right] d t \mid \\
\leqq & \left|2^{-n-1} \int_{0}^{1} D_{k^{\prime}}(0)\left[f\left(x+t / 2^{n+1}\right)-f\left(x+(t+1) / 2^{n+1}\right)\right] d t\right| \\
& +\left|\sum_{p=1}^{2^{n-1}} 2^{-n-1} \int_{0}^{1} \cdots d t\right| \\
\leqq & 2^{-n-1} \cdot k^{\prime} \cdot \omega\left(f, 2^{-n-1}\right)+\left|\int_{0}^{1}\left(2^{-n-1} \sum_{p=1}^{2^{n}-1} \cdots\right) d t\right|=B_{1}+B_{2} .
\end{aligned}
$$

Using the fact that for $u \in(0,1),\left|D_{k}(u)\right|<2 u^{-1}$, [2], Lemma 1 , we obtain the following inequality for the integrand, $I$, of $B_{2}$ :

$$
\begin{aligned}
|I| \leqq & \sum_{p=1}^{2^{n}-1} 2^{-n-1} \cdot 2^{n+1} \cdot p^{-1} \mid f\left(x+(t+2 p) / 2^{n+1}\right) \\
& -f\left(x+(t+2 p+1) / 2^{n+1}\right) \mid .
\end{aligned}
$$

Now we observe that for every $t \in[0,1)$ there is an $\tilde{x} \in[0,1), \widetilde{x}=\widetilde{x}(t)$, such that $x+(t+q) / 2^{n+1}=\tilde{x}+q / 2^{n+1}$ for all $q=1,2, \cdots, 2^{n+1}-1$. Therefore 


$$
|I| \leqq \sum_{p=1}^{2^{n}-1} p^{-1}\left|f\left(\widetilde{x}+2 p / 2^{n+1}\right)-f\left(\widetilde{x}+(2 p+1) / 2^{n+1}\right)\right|=U_{n}(\widetilde{x}) .
$$

Under the hypothesis of our theorem $U_{n}(\widetilde{x}) \rightarrow 0$ uniformly in $\widetilde{x}$ as $n \rightarrow \infty$. This implies that $B_{2} \rightarrow 0$ uniformly in $x$ as $n \rightarrow \infty$, and so, $\lim _{k \rightarrow \infty}\left(S_{k}(f, x)-f(x)\right)=0$ uniformly in $x$.

4. In this section we will show that our main theorem implies two classical results for WFS. The first is the Dini-Lipschitz test for WFS, which was first proved in [2], Th. XIII. A generalization of it can be found in [5], $\S(3.5)$.

CoROLlaRY 1. Let $f(x)$ be a continuous function of period 1 and let $\omega(f, \delta)=o\left(\log \delta^{-1}\right)^{-1}$ as $\delta \rightarrow 0$. Then the WFS of $f(x)$ converges uniformly to $f(x)$.

Proof. We see immediately that

$$
\left|U_{n}(x)\right| \leqq \sum_{p=1}^{2^{n}-1} p^{-1} \omega\left(f, 2^{-n-1}\right) \leqq \omega\left(f, 2^{-n-1}\right) C \log 2^{n}
$$

for some constant $C$. Thus $\lim _{n \rightarrow \infty} U_{n}(x)=0$ uniformly in $x$.

The next corollary is Jordan's test for WFS, which was first proved in [6], Th. IV.

CoRollary 2. Let $f(x)$ be a continuous function of period 1 . If $f(x)$ is of bounded variation on $[0,1]$, then its WFS converges uniformly to $f(x)$.

Proof. We can find a nondecreasing sequence of natural numbers $\{m(n)\}$ such that (a) $m(n)<2^{n}-1$ for all $\mathrm{n}$, (b) $m(n) \rightarrow \infty$ as $n \rightarrow \infty$, (c) $\omega\left(f, 2^{-n-1}\right) \log m(n) \rightarrow 0$ as $n \rightarrow \infty$. Then,

$$
\begin{aligned}
U_{n}(x) \mid \leqq & \omega\left(f, 2^{-n-1}\right)\left[1+\frac{1}{2}+\cdots+\frac{1}{m(n)}\right] \\
& +\sum_{p=m(n)+1}^{2^{n}-1} p^{-1}\left|f\left(x+2 p / 2^{n+1}\right)-f\left(x+(2 p+1) / 2^{n+1}\right)\right| \\
\leqq & C \omega\left(f, 2^{-n-1}\right) \log m(n)+(m(n)+1)^{-1} \operatorname{Var}(f) .
\end{aligned}
$$

Thus $\lim _{n \rightarrow \infty} U_{n}(x)=0$ uniformly in $x$.

Finally we will prove a theorem for WFS analogous to certain results of L. C. Young [7] and R. Salem [4] for TFS, and which is an extension of Jordan's theorem. First we will give a definition of bounded $\Phi$-variation. 
Let $\varphi(u)$ be a continuous, strictly increasing function defined for $u \geqq 0$, such that $\varphi(0)=0$ and $\lim _{u \rightarrow \infty} \varphi(u)=\infty$. Let $\psi$ be the inverse of $\varphi$. Next, let $\Phi(u)=\int_{0}^{u} \varphi(t) d t$ and $\Psi(u)=\int_{0}^{u} \psi(t) d t$. Functions so obtained, are called complementary in the sense of W. H. Young, and they satisfy the following inequality, due to W. H. Young: if $a, b \geqq 0$, then $a b \leqq \Phi(a)+\Psi(b)$, see [8], p. 16 .

Definition. A function $f(x)$ on $[0,1)$ is said to be of bounded $\Phi$-variation if there is an $M<\infty$ such that for each finite partition $0 \leqq x_{1}<x_{2} \cdots<x_{n} \leqq 1$ we have $\sum_{i=1}^{n-1} \Phi\left(\left|f\left(x_{i+1}\right)-f\left(x_{i}\right)\right|\right)<M$.

We can prove the following

CoRollary 3. Let $\Phi(x)$ and $\Psi(x)$ be functions complementary in the sense of $W$. H. Young and let $\sum_{k=1}^{\infty} \Psi\left(k^{-1}\right)<\infty$. Let $f(x)$ be a continuous function of period 1 and of bounded $\Phi$-variation. Then $\lim _{n \rightarrow \infty} S_{n}(f, x)=f(x)$ uniformly in $x$.

Proof. Since $\sum_{k=1}^{\infty} \Psi\left(k^{-1}\right)<\infty$, we can find a sequence $\{\varepsilon(k)\}$ of positive numbers, decreasing to 0 as $k \rightarrow \infty$, and for which

$$
\left.\sum_{k=1}^{\infty} \Psi(k \varepsilon(k))^{-1}\right)<\infty
$$

Let

$$
\left|f\left(x+2 p / 2^{n+1}\right)-f\left(x+(2 p+1) / 2^{n+1}\right)\right|=\Delta_{p} .
$$

Then, according to Young's inequality, we have

$$
\Delta_{p} \cdot(p \varepsilon(p))^{-1} \leqq \Phi\left(\Delta_{p}\right)+\Psi\left((p \varepsilon(p))^{-1}\right) .
$$

From our hypothesis it follows that there is a constant $N<\infty$ such that for each $m$

$$
\sum_{p=m}^{2^{n}-1} \Delta_{p}(p \varepsilon(p))^{-1} \leqq \sum_{p=m}^{2^{n}-1} \Phi\left(\Delta_{p}\right)+\sum_{p=m}^{2^{n}-1} \Psi\left((p \varepsilon(p))^{-1}\right)<N .
$$

Therefore,

$$
\sum_{p=m}^{2^{n}-1} \Delta_{p} p^{-1}<N \varepsilon(m)
$$

Choosing $\{m(n)\}$ as in the proof of Corollary 2, we have

$$
\left|U_{n}(x)\right| \leqq \omega\left(f, 2^{-n-1}\right)\left[1+\frac{1}{2}+\cdots+\frac{1}{m(n)}\right]+N \varepsilon(m(n)+1),
$$

i.e., $U_{n}(x) \rightarrow 0$ uniformly in $x$ as $n \rightarrow \infty$. 
The author wishes to express his gratitude to Professor D. Waterman for bringing this problem to his attention and for his encouragement during its solution.

\section{REFERENCES}

1. N. K. Bary, A Treatise on trigonometric series, MacMillan, New York, 1964.

2. N. J. Fine, On the Walsh functions, Trans. Amer. Math. Soc. 65 (1949), 372-414.

3. R. E. A. C. Paley, A remarkable series of orthogonal functions, Proc. London Math. Soc. 34 (1932), 241-279.

4. R. Salem, Essais sur les séries trigonométriques, Actual. Sci. et Industr., No. 862, Paris, 1940.

5. N. Ya. Vilenkin, On a class of complete orthonormal systems, Transl. Amer. Math. Soc. (2) 28 (1963), 1-35.

6. J. L. Walsh, $A$ closed set of normal orthogonal functions, Amer. J. Math. 55 (1923), 5-24.

7. L. C. Young, Sur une généralisation de la notion de variation de puissance p-ième bornée au sens de M. Wiener, et sur la convergence des séries de Fourier, C. R. Acad. Sci. Paris 204 (1937), 470-472.

8. A Zygmund, Trigonometric series I, 2nd ed., Cambridge University Press, 1959.

Received June 9, 1969.

California State College at Hayward

University of New Mexico, Albuquerque 


\section{PACIFIC JOURNAL OF MATHEMATICS}

EDITORS

H. SAMELSON

Stanford University

Stanford, California 94305

RichaRd PIERCE

University of Washington

Seattle, Washington 98105
J. DUGUNDJI

Department of Mathematics

University of Southern California

Los Angeles, California 90007

RICHARD ARENS

University of California

Los Angeles, California 90024

\section{ASSOCIATE EDITORS}

E. F. BECKENBACH

B. H. NeumanN

F. WOLF

K. YOSHIDA

\section{SUPPORTING INSTITUTIONS}

UNIVERSITY OF BRITISH COLUMBIA

CALIFORNIA INSTITUTE OF TECHNOLOGY

UNIVERSITY OF CALIFORNIA

MONTANA STATE UNIVERSITY

UNIVERSITY OF NEVADA

NEW MEXICO STATE UNIVERSITY

OREGON STATE UNIVERSITY

UNIVERSITY OF OREGON

OSAKA UNIVERSITY

UNIVERSITY OF SOUTHERN CALIFORNIA
STANFORD UNIVERSITY

UNIVERSITY OF TOKYO

UNIVERSITY OF UTAH

WASHINGTON STATE UNIVERSITY

UNIVERSITY OF WASHINGTON

AMERICAN MATHEMATICAL SOCIETY CHEVRON RESEARCH CORPORATION TRW SYSTEMS

NAVAL WEAPONS CENTER 


\section{Pacific Journal of Mathematics}

May, 1970

Johan Aarnes, Edward George Effros and Ole A. Nielsen, Locally compact

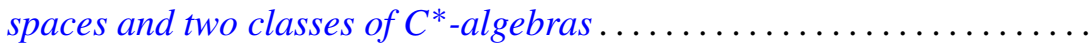

Allan C. Cochran, R. Keown and C. R. Williams, On a class of topological

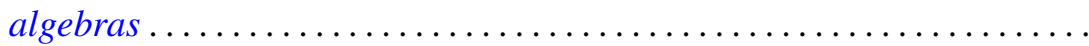

John Dauns, Integral domains that are not embeddable in division rings ....

Robert Jay Daverman, On the number of nonpiercing points in certain

crumpled cubes.....................................

Bryce L. Elkins, Characterization of separable ideals ................

Zbigniew Fiedorowicz, A comparison of two naturally arising uniformities

on a class of pseudo-PM spaces ...........................

Henry Charles Finlayson, Approximation of Wiener integrals of functionals

continuous in the uniform topology ........................

Theodore William Gamelin, Localization of the corona problem ...........

Alfred Gray and Paul Stephen Green, Sphere transitive structures and the

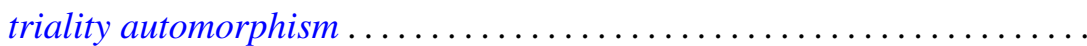

Charles Lemuel Hagopian, On generalized forms of aposyndesis ..........

J. Jakubík, On subgroups of a pseudo lattice ordered group ...............

Cornelius W. Onneweer, On uniform convergence for Walsh-Fourier

series..................................

Stanley Joel Osher, On certain Toeplitz operators in two variables ...

Washek (Vaclav) Frantisek Pfeffer and John Benson Wilbur, On the

measurability of Perron integrable functions............

Frank J. Polansky, On the conformal mapping of variable regions...

Kouei Sekigawa and Shûkichi Tanno, Sufficient conditions for a Riemannian manifold to be locally symmetric ...................

James Wilson Stepp, Locally compact Clifford semigroups ....

Ernest Lester Stitzinger, Frattini subalgebras of a class of solvable Lie

algebras ................................

George Szeto, The group character and split group algebras...

Mark Lawrence Teply, Homological dimension and splitting torsion

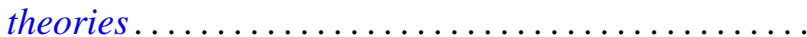

David Bertram Wales, Finite linear groups of degree seven. II ...

Robert Breckenridge Warfield, Jr., An isomorphic refinement theorem for

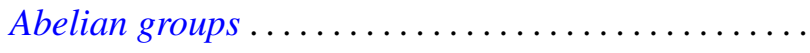

James Edward West, The ambient homeomorphy of an incomplete subspace

of infinite-dimensional Hilbert spaces................

Peter Wilker, Adjoint product and hom functors in general topology ...

Daniel Eliot Wulbert, A note on the characterization of conditional 